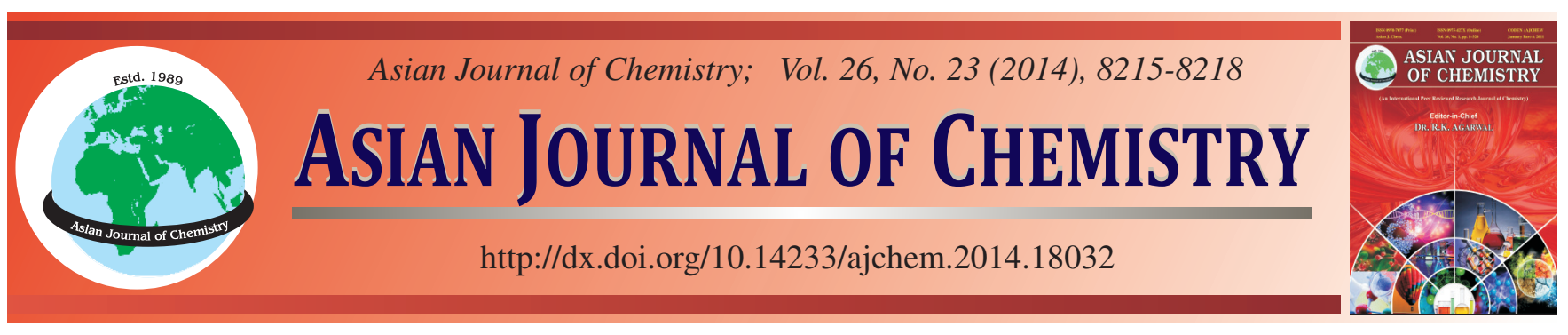

\title{
Fabrication of Iron or Cobalt-Doped Carbon-Based Catalysts for Oxygen Reduction Reaction Using Soy Protein As Specific Nitrogen Precursor
}

\author{
Chaozhong Guo ${ }^{1,2,3, *}$, Liangliang Tian ${ }^{1}$, Wenli Liao $^{4, *}$ and Changguo Chen ${ }^{2, *}$
}

${ }^{1}$ Research Institute for New Materials Technology, Chongqing University of Arts and Sciences, Yongchuan 402160, P.R. China ${ }^{2}$ College of Chemistry and Chemical Engineering, Chongqing University, Chongqing 400044, P.R. China

${ }^{3}$ Chongqing Key Laboratory of Environmental Materials \& Remediation Technologies, Chongqing University of Arts and Sciences, Yongchuan 402160, P.R. China

${ }^{4}$ College of Materials and Chemical Engineering, Chongqing University of Arts and Sciences, Chongqing 402160, P.R. China

*Corresponding authors: Tel: +86 23 65111357; E-mail: guochaozhong1987@163.com, cgchen@cqu.edu.cn

\begin{abstract}
We here design two kinds of non-precious metal electrocatalysts (Fe-SP/C900 and Co-SP/C900) for oxygen reduction reaction by thermally treating a mechanical mixture of soy protein powder, carbon black and iron chloride or cobalt chloride at $900{ }^{\circ} \mathrm{C}$ for $2 \mathrm{~h}$ under the $\mathrm{N}_{2}$ atmosphere. The linear sweep voltammetry is used to evaluate the oxygen reduction reaction catalytic activities of Fe-SP/C900 and $\mathrm{Co-SP/C900.} \mathrm{The} \mathrm{oxygen} \mathrm{reduction} \mathrm{reaction} \mathrm{onset} \mathrm{potential} \mathrm{of} \mathrm{Fe}-\mathrm{SP} / \mathrm{C} 900$ is about $0.10 \mathrm{~V}(v \mathrm{~s}$. $\mathrm{Hg} / \mathrm{HgO})$ at a scan rate of $5 \mathrm{mV} \mathrm{s}{ }^{-1}$ in 0.1 mol L $\mathrm{L}^{-1} \mathrm{KOH}$ solution and the catalytic activity of Fe-SP/C900 is much better than that of Co-SP/C 900 . The formation of oxygen reduction reaction-active sites of $\mathrm{Fe}-\mathrm{SP} / \mathrm{C} 900$ and $\mathrm{Co}-\mathrm{SP} / \mathrm{C} 900 \mathrm{can}$ be facilitated by metallic iron and cobalt, respectively, but the metallic iron may play a more important role in improving the formation of active sites, resulting in the enhanced oxygen reduction reaction catalytic activity of Fe-SP/C900. Present study will encourage researchers to produce new catalytic materials for oxygen reduction using bio-proteins as specific nitrogen precursors.
\end{abstract}

Keywords: Soy protein, Nitrogen precursor, Electrocatalyst, Oxygen reduction reaction.

\section{INTRODUCTION}

High efficiency of cathodic catalysts is an important factor in improving the performance of low-temperature fuel cells ${ }^{1}$. So far, carbon-supported platinum particles are still the most efficient catalysts for oxygen reduction reaction either in acidic or alkaline media ${ }^{2}$. However, the high cost and limited resources of platinum have hindered the large-scale application of the Pt-based catalysts, which further causes their commercial way to be difficult ${ }^{3}$. The crossover effects of fuels such as the methanol molecule occurred at the Pt-based catalysts can produce a "mixed potential" and decrease the potential of the oxygen reduction reaction, resulting in a loss of cell voltage $\mathrm{e}^{4}$. Therefore, the development of the electrocatalysts with high activity, long-term stability and low cost to substitute for Ptbased oxygen reduction reaction catalysts is therefore of paramount importance.

Previous evidence has primarily focused on the development of non-precious metal catalysts and non-platinum cathode catalysts for oxygen reduction reaction ${ }^{5}$. Cobalt phthalocyanine with the oxygen reduction reaction electro- catalytic activity in alkaline media ${ }^{6}$, various organometallic complexes containing $\mathrm{N}_{\mathrm{x}}$-macrocyclic (metal- $\mathrm{N}_{\mathrm{x}}$ ) structures, especially for $\mathrm{Fe}$ - and Co-based porphyrins and related derivatives, have been developed as promising alternatives for Pt-based catalysts ${ }^{7}$. Interestingly, the heat-treatment of metal$\mathrm{N}_{\mathrm{x}}$ macrocycles could largely improve their oxygen reduction reaction catalytic activity and stability ${ }^{5,7}$ and were labeled as TM-N/C (TM = Co, Fe, Ni, Mn, etc.). However, the TM-N/C catalysts have traditionally prepared by using a complicate method of wet-impregnation based on a principle of transition metal ions chelating with macrocyclic compounds. Organometallic $\mathrm{N}_{\mathrm{x}}$-macrocyclic complexes are replaced by other nitrogen-containing compounds to synthesize the TM-N/C catalysts, such as polyaniline ${ }^{8}$, polypyrrole ${ }^{9}$, urea ${ }^{10}$, phenanthroline $^{11}$, hemoglobin ${ }^{12}$, blood protein ${ }^{13-15}$, egg-white protein ${ }^{16}$, etc., which mainly focus on the selection of nitrogen precursors to form the catalytically active sites for the oxygen reduction reaction.

Here we introduce a low-cost method of synthesizing the carbon-supported catalysts (Fe-SP/C900 and Co-SP/C900) by separately heat-treating two types of mechanical mixtures 
involving soy protein, carbon black and cobalt chloride or iron chloride under the nitrogen atmosphere. The precursor preparation has been completed by a facile mechanical mixing method other than producing a chemical "complex". Our study will inspire researchers to design carbon-based oxygen reduction reaction catalysts by utilizing bioproteins as nitrogen sources of active sites.

\section{EXPERIMENTAL}

Soy protein powder (particle diameter $\approx 200 \mu \mathrm{m}$ ) was supplied by the Food Testing Center of Chongqing Bureau of Quality and Technology Supervision. Carbon black (Vulcan $\mathrm{XC}-72 \mathrm{R}, \mathrm{VCB}$ ) was purchased from Cabot ${ }^{\circledR}$ and pretreated in $4.5 \mathrm{~mol} \mathrm{~L}^{-1} \mathrm{HNO}_{3}$ solution at $80{ }^{\circ} \mathrm{C}$ for $12 \mathrm{~h}$.

Preparation and characteriazation of $\mathrm{Fe}$ - and Co-based catalysts: For the preparation of the catalysts, $0.50 \mathrm{~g}$ of soy protein powder, $0.25 \mathrm{~g}$ of the treated $\mathrm{VCB}$ and $0.38 \mathrm{~g}$ of iron chloride $\left(\mathrm{FeCl}_{3} \cdot 6 \mathrm{H}_{2} \mathrm{O}, \mathrm{AR}\right)$ or $0.3 \mathrm{~g}$ of cobalt chloride $\left(\mathrm{CoCl}_{2} \cdot 6 \mathrm{H}_{2} \mathrm{O}, \mathrm{AR}\right)$ were mechanically mixed in an agate mortar for $0.5 \mathrm{~h}$. The obtained precursors were inserted into a tube furnace for heat-treating at $900{ }^{\circ} \mathrm{C}$ for $2 \mathrm{~h}$ in $\mathrm{N}_{2}$ atmosphere with a flow rate of $0.50 \mathrm{~L} \mathrm{~min}^{-1}$. The yielded catalysts were marked as Fe-SP/C900 and Co-SP/C900, respectively. Besides, the SP/C900 sample was fabricated by the pyrolysis of the precursor containing the soy protein power $(0.5 \mathrm{~g})$ and carbon black $(0.25 \mathrm{~g})$ and the Fe/C900 sample was also prepared by heat-treating a mixture of carbon black and $\mathrm{FeCl}_{3} \cdot 6 \mathrm{H}_{2} \mathrm{O}$ assuring that the content of iron metal was identical to the FeSP/C precursor (7 wt. \% Fe). The X-ray diffraction (XRD) phase analysis was performed using Shimadzu XRD-6000 (Japan)

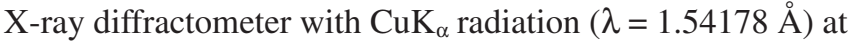
$4^{\circ} \mathrm{min}^{-1}$.

Electrochemical measurements: The oxygen reduction reaction catalytic activity of the catalysts was evaluated by linear sweep voltammetry (LSV). Electrochemical experiments were conducted on a $\mathrm{CHI} 600 \mathrm{~A}$ electrochemical workstation ( $\mathrm{CH}$ instruments, USA). A Pt wire and an $\mathrm{Hg} / \mathrm{HgO} / 1 \mathrm{~mol} \mathrm{~L}^{-1}$ $\mathrm{KOH}$ were used as the counter and reference electrodes, respectively. The working electrode was a glassy carbon electrode (GCE, $\phi=5 \mathrm{~mm}$ ) covered with a thin layer of nafion-impregnated catalysts. $10 \mu \mathrm{L}$ catalyst ink, well-dispersed by $0.5 \mathrm{wt}$. \% nafion solution/ultrapure water, was dropped onto the glassy carbon electrode surface and then dried naturally at room temperature. The mass loading of the catalysts is $2.5 \mathrm{mg} \mathrm{cm}^{-2}$. All the oxygen reduction reaction experiments were performed over the potential range of 0.3 to $-0.7 \mathrm{~V}$ at a scan rate of $5 \mathrm{mV} \mathrm{s}^{-1}$ in $\mathrm{O}_{2}$-saturated $0.1 \mathrm{~mol} \mathrm{~L}^{-1} \mathrm{KOH}$ solution. All the electrochemical measurements were carried out at room temperature.

\section{RESULTS AND DISCUSSION}

Electrocatalytic activities of VCB, Fe/C900, SP/C900 and $\mathrm{Fe}-\mathrm{SP} / \mathrm{C900}$ towards oxygen reduction reaction: Fig. 1 shows the linear sweep voltammograms of VCB, Fe/C900, SP/C900 and Fe-SP/C900 in $\mathrm{O}_{2}$-saturated $0.1 \mathrm{~mol} \mathrm{~L}^{-1} \mathrm{KOH}$ solution. The onset potential, peak potential and peak current from the LSV tests were used as the main parameters of evaluating the oxygen reduction reaction catalytic activity. The SP/C900 exhibits a higher oxygen reduction reaction catalytic activity with an onset potential of $-0.05 \mathrm{~V}$ and a peak potential of $-0.15 \mathrm{~V}$ compared to the commercial carbon black, indicating the carbon black can interact with the $N$-containing decomposed products of soy protein at high temperature to produce the catalytically active sites for oxygen reduction reaction. Additionally, the Fe/C900 has good catalytic activity in alkaline media. Based on the analysis of three parameters, the Fe-SP/C900 exhibits the best oxygen reduction reaction catalytic performance with an onset potential of $\sim 0.10 \mathrm{~V}$ and a peak potential of $-0.03 \mathrm{~V}$, nearly identical to those of the $\mathrm{Pt} / \mathrm{C}$ catalyst ${ }^{17}$. Moreover, the oxygen reduction reaction peak current of Fe-SP/C900 is twice as large as that of SP/C900. It suggests that the addition of iron chloride into the precursor plays an important role in enhancing the oxygen reduction reaction catalytic activity of the obtained catalyst for hightemperature pyrolysis process. After Fe-SP/C900 was subjected to the leaching experiment in $5 \mathrm{~mol} \mathrm{~L}^{-1} \mathrm{HCl}$ solutions for $12 \mathrm{~h}$, the color of soaking solution was changed to the yellow of ferric ions, indicating that the metallic iron species has been dissolved out. The catalytic activity of leached sample (Fe-SP/ C900A) has been also exhibited at Fig. 1 and is also better than that of the catalyst SP/C900 or Fe/C900 as before. It shows that the metal source of $\mathrm{Fe}$, the $\mathrm{N}$ source of soy protein and the support of VCB in the precursor is indispensable for the fabrication of the $\mathrm{Fe}-\mathrm{SP} / \mathrm{C}$ electrocatalyst with high oxygen reduction reaction catalytic activity.

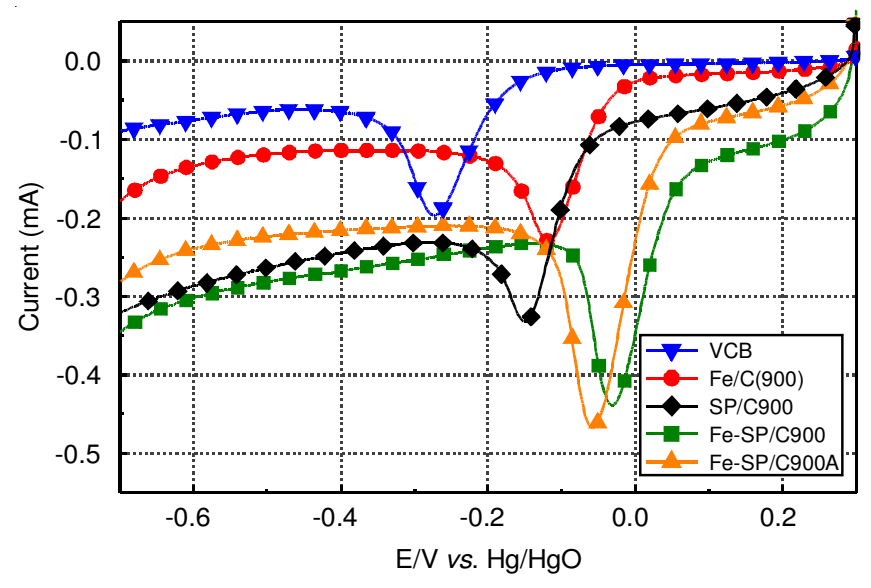

Fig. 1. Linear sweep voltammograms of VCB, Fe/C900, SP/C900, Fe-SP/ $\mathrm{C} 900$ before and after acid-treatment in $\mathrm{O}_{2}$-saturated $0.1 \mathrm{~mol} \mathrm{~L}^{-1}$ $\mathrm{KOH}$ solution

XRD analysis of SP/C900, Fe/C900 and Fe-SP/C900: The XRD patterns of SP/C900, Fe/C900 and Fe-SP/C900 are showed in Fig. 2. For SP/C900, the only other peaks observed are two amorphous-carbon peaks, centered at $2 \theta$ values of about $24^{\circ}$ and about $44^{\circ}$, which are ascribed to the graphitic planes (002) and (101), respectively ${ }^{13}$. Comparing to the XRD pattern of the $\mathrm{VCB}^{15}$, the $2 \theta$ value of graphitic plane (002) becomes smaller and also the width of two diffraction peaks increases largely, which can be affected by lower graphitization degree. The carbon black can be covered or modified by the pyrolyzed products of soy protein power, which is supported by our previous reports ${ }^{10,15,16}$. Two diffraction peaks at about $55^{\circ}$ and about $65^{\circ}$ can be assigned to the metallic iron as a form of face-centered cubic structure $(\alpha-\mathrm{Fe})$ in the $\mathrm{Fe} / \mathrm{C} 900$ 


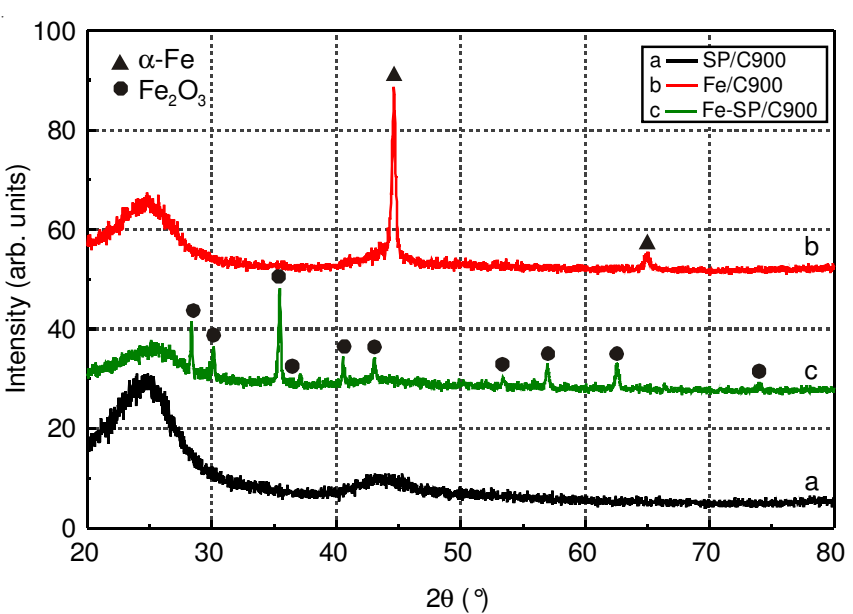

Fig. 2. X-ray diffraction spectra of SP/C900, Fe/C900 and Fe-SP/C900

sample. However, a set of sharp peaks at 28.2, 30.2, 35.6, 37.3, $40.4,43.8,53.6,57.4,62.8$ and $74.1^{\circ}$ can be attributed to the iron oxide (PDF \#39-1346), but the metallic iron does not occur at the Fe-SP/C900 catalyst. The correlation between the XRD pattern and the oxygen reduction reaction activity reveals that the $\mathrm{Fe}(\mathrm{III})$ ions are firstly reduced to lower valence metallic iron by carbon black at heat-treating process of the nitrogen atmosphere, which is used to facilitate more active sites to be formed and further improves the oxygen reduction reaction catalytic activity of the Fe-SP/C900, but it will be rapidly re-oxidized by the oxygen-containing decomposed moiety of soy protein at high temperature. In addition, the iron oxides are not the active site of the $\mathrm{Fe}$-SP/C900 and the metallic iron may not involve in the formation of the active site based on the obtained result of the leaching experiment in $\mathrm{HCl}$ solution ${ }^{11}$.

Electrocatalytic activities of $\mathrm{Fe}-\mathrm{SP} / \mathrm{C} 900$ and $\mathrm{Co}-\mathrm{SP} /$ C900 towards oxygen reduction reaction: Fig. 3 shows the linear sweep voltammograms of Fe-SP/C900 and Co-SP/C900 in $0.1 \mathrm{~mol} \mathrm{~L}^{-1} \mathrm{KOH}$ solution saturated by $\mathrm{O}_{2}$. It is found that different kinds of metal source in the precursor will result in a large difference in the oxygen reduction reaction catalytic activity of the obtained electrocatalysts after doing the pyrolysis process. The $0.02 \mathrm{~V}$ of oxygen reduction reaction onset potential and $-0.10 \mathrm{~V}$ of oxygen reduction reaction peak potential of $\mathrm{Co}-\mathrm{SP} / \mathrm{C} 900$ are more negative than those of $\mathrm{Fe}-\mathrm{SP} / \mathrm{C} 900$, although the oxygen reduction reaction peak current of the

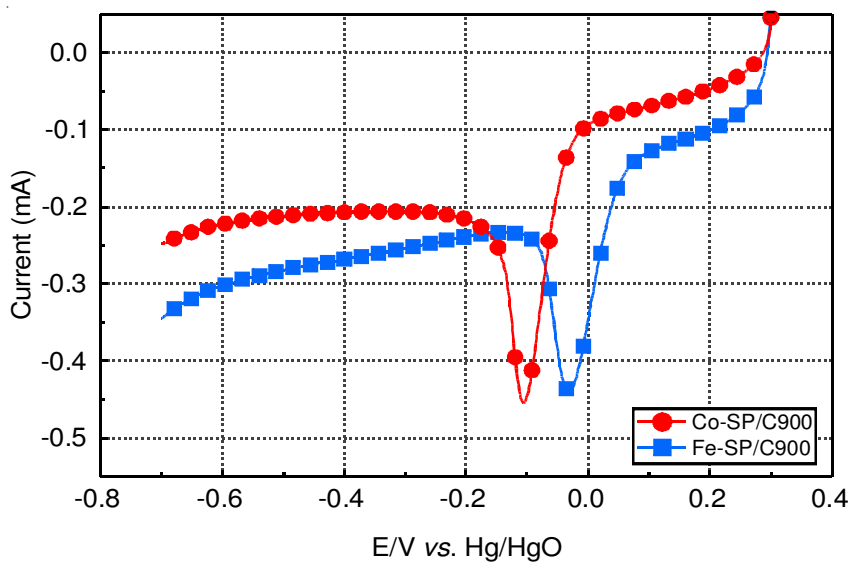

Fig. 3. Linear sweep voltammograms of Fe-SP/C900 and Co-SP/C900 in $\mathrm{O}_{2}$-saturated $0.1 \mathrm{~mol} \mathrm{~L}^{-1} \mathrm{KOH}$ solution former is slightly superior to that of the latter. It provides solid evidence for assuring that the catalytic activity of Fe-SP/C900 is better than that of Co-SP/C900, which is in accordance with reported results ${ }^{6}$.

XRD analysis of Fe-SP/C900 and Co-SP/C900: In Fig. 4, the XRD patterns of Fe-SP/C900 and Co-SP/C900 show different phase compositions. The $\mathrm{Co}(\mathrm{II})$ ions has been reduced to the crystalline phase of metallic cobalt $(\beta-\mathrm{Co})$ by carbon black at high temperature under the inert atmosphere, resulting in the existence of a set of sharp peaks at 44.2, 51.2 and 75.8 . A distinctive finding is that the metallic cobalt is difficult to re-oxidize by the oxygen-containing decomposed groups. The occurrence of metallic cobalt can also help to form more active sites for the oxygen reduction reaction on the modified carbons with $N$-containing groups created from the decomposition of soy protein during high-temperature pyrolysis ${ }^{9,10}$. Besides, combining the XRD analysis with the catalytic activity evaluation indicates that a greater improved performance of metallic iron in the formation of catalytically active sites than that of metallic cobalt may produce a higher electrocatalytic activity towards oxygen reduction reaction of $\mathrm{Fe}-\mathrm{SP} / \mathrm{C} 900$.

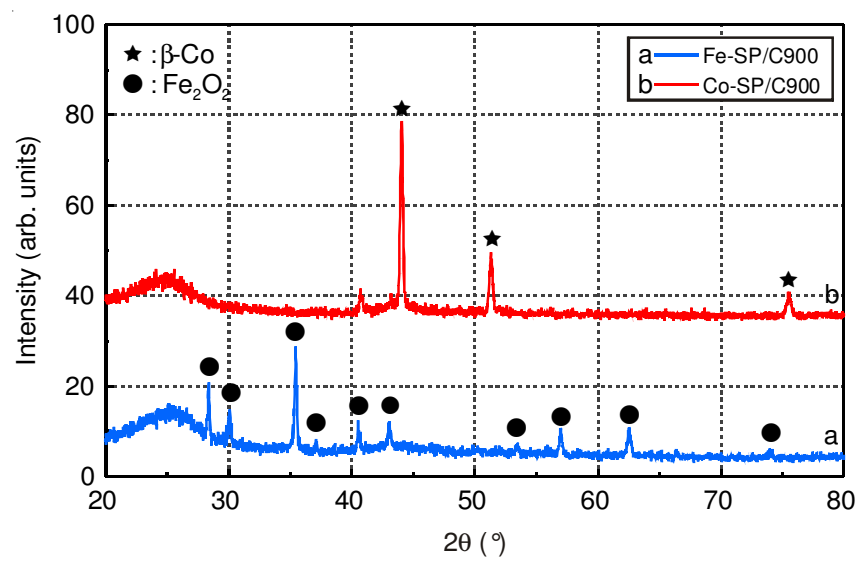

Fig. 4. X-ray diffraction spectra of Fe-SP/C900 and Co-SP/C900

\section{Conclusion}

Herein, two kinds of highly-active oxygen reduction reaction electrocatalysts (Fe-SP/C900 and Co-SP/C900) were prepared from heat-treating the mechanical mixtures of soy protein powder, carbon black and metal salts by a facile solid-state mixing method. The formation of active sites for the oxygen reduction reaction of the catalysts can be largely facilitated and promoted by the metallic iron or cobalt obtained from the reduction of higher valence metallic ions by carbon black at high-temperature process under the $\mathrm{N}_{2}$ atmosphere. However, metallic iron may play a more important role in catalyzing the formation of active sites, resulting in a higher electrocatalytic activity of Fe-SP/C900 toward the oxygen reduction reaction.

\section{ACKNOWLEDGEMENTS}

This work was financially supported by the Natural Science Fund of China (No. 21273292), the Fundation of Scientific and Technological Research Program of Chongqing Municipal Education Commission (No. KJ121213) and the Talent Introduction Foundation of Chongqing University of Arts and Sciences (No. R2012c114). 


\section{REFERENCES}

1. B.C.H. Steele and A. Heinzel, Nature, 414, 345 (2001).

2. F.B. Su, Z.Q. Tian, C.K. Poh, Z. Wang, S.H. Lim, Z.L. Liu and J.Y. Lin, Chem. Mater., 22, 832 (2010).

3. B. Lim, M.J. Jiang, P.H.C. Camargo, E.C. Cho, J. Tao, X.M. Lu, Y.M. Zhu and Y.N. Xia, Science, 324, 1302 (2009)

4. Y.M. Yu, J.H. Zhang, C.H. Xiao, J.D. Zhong, X.H. Zhang and J.H Chen, Fuel Cells, 12, 506 (2012)

5. B. Wang, J. Power Sources, 152, 1 (2005).

6. C.W.B. Bezerra, L. Zhang, K.C. Lee, H.S. Liu, A.L.B. Marques, E.P. Marques, H.J. Wang and J.J. Zhang, Electrochim. Acta, 53, 4937 (2008).

7. R. Jasinski, Nature, 201, 1212 (1964).

8. G. Wu, K.L. More, C.M. Johnston and P. Zelenay, Science, 332, 443 (2011)
9. K. Lee, L. Zhang, H. Lui, R. Hui, Z. Shi and J. Zhang, Electrochim. Acta, 54, 4704 (2009).

10. M. Lefèvre, E. Proietti, F. Jaouen and J.P. Dodelet, Science, 324, 71 (2009).

11. Y.J. Si, C.G. Chen, W. Yin and H. Cai, Chin. J. Chem. Phys., 23, 331 (2010).

12. J. Maruyama and I. Abe, Chem. Mater., 18, 1303 (2006).

13. C.Z. Guo, C.G. Chen and Z.L. Luo, Int. J. Electrochem. Sci., 8, 8940 (2013).

14. C.Z. Guo, C.G. Chen and Z.L. Luo, Chin. Sci. Bull., 58, 3698 (2013).

15. C.Z. Guo, C.G. Chen and Z.L. Luo, J. Power Sources, 245, 841 (2014).

16. P. Liu, C.G. Chen, C.Z. Guo, M. Du, H.J. Wu and W. Yin, Asian J. Chem., 26, 2523 (2014).

17. X.G. Fu, Y.R. Liu, X.P. Cao, J.T. Jin, Q. Liu and J.Y. Zhang, Appl. Catal. B, 130-131, 143 (2013). 